\title{
Null controllability of a semilinear degenerate parabolic equation with a gradient term
}

\author{
Fengdan $\mathrm{Xu}^{1}$, Qian Zhou $^{1 *}$ and Yuanyuan Nie ${ }^{1}$
}

\section{"Correspondence:}

zhouqian@jlu.edu.cn

${ }^{1}$ School of Mathematics, Jilin

University, Changchun, P.R. China

\section{Springer}

\begin{abstract}
This paper concerns the null controllability of a semilinear control system governed by degenerate parabolic equation with a gradient term, where the nonlinearity of the problem is involved with the first derivative. We first establish the well-posedness and prove the approximate null controllability of the linearized system, then we can get the approximate null controllability of the semilinear control system by a fixed point argument. Finally, the semilinear control system with a gradient term is shown to be null controllable.
\end{abstract}

Keywords: Null controllability; The semilinear problem; Degenerate parabolic equation

\section{Introduction}

In this paper, we investigate the null controllability of the following semilinear degenerate system:

$$
\begin{aligned}
& u_{t}-\left(x^{\alpha} u_{x}\right)_{x}+g\left(x, t, u, u_{x}\right)=h(x, t) \chi_{\omega}, \quad(x, t) \in Q_{T}, \\
& u(0, t)=u(1, t)=0 \quad \text { if } 0<\alpha<1, t \in(0, T), \\
& x^{\alpha} u_{x}(0, t)=u(1, t)=0 \quad \text { if } 1 \leq \alpha<2, t \in(0, T), \\
& u(x, 0)=u_{0}(x), \quad x \in(0,1),
\end{aligned}
$$

where $Q_{T}=(0,1) \times(0, T), \omega$ is a nonempty open subset of $(0,1), u_{0} \in L^{2}(0,1), h(x, t) \in$ $L^{2}\left(Q_{T}\right)$ is a control function, $g(x, t, s, p)$ is Lebesgue measurable in $Q_{T} \times \mathbb{R} \times \mathbb{R}$ and $C^{1}$ continuous with respect to $s, p$ uniformly for $(x, t) \in Q_{T}$. Furthermore, we assume that $g$ satisfies $g(\cdot, \cdot, 0,0)=0$ and

$$
\left|g_{s}(x, t, s, p)\right|+x^{-\alpha / 2}\left|g_{p}(x, t, s, p)\right| \leq K, \quad \forall(x, t, s, p) \in Q_{T} \times \mathbb{R} \times \mathbb{R},
$$

where $K>0$ is a constant. Equation (1.1) is degenerate at the boundary $x=0$, and it can be used to describe some physical models, for example, in $[6,8]$, we can find a motivating

(c) The Author(s) 2020. This article is licensed under a Creative Commons Attribution 4.0 International License, which permits use sharing, adaptation, distribution and reproduction in any medium or format, as long as you give appropriate credit to the original author(s) and the source, provide a link to the Creative Commons licence, and indicate if changes were made. The images or other third party material in this article are included in the article's Creative Commons licence, unless indicated otherwise in a credit line to the material. If material is not included in the article's Creative Commons licence and your intended use is not permitted by statutory regulation or exceeds the permitted use, you will need to obtain permission directly from the copyright holder. To view a copy of this licence, visit http://creativecommons.org/licenses/by/4.0/. 
example of a Crocco-type equation coming from the study on the velocity field of a laminar flow on a flat plate.

In the last forty years, many authors have been devoted to studying control systems, the interested readers can refer to [1-26] and the references therein. For instance, Wang in [27-29] studied the approximate controllability of a class of systems governed by degenerate parabolic equations. In 2013, Du and Wang in [11] investigated the null controllability of a class of coupled degenerate systems. Later, $\mathrm{Du}$ and $\mathrm{Xu}$ in [13] studied the boundary controllability of a semilinear degenerate system with convection term. Recently, Xu, Wang and Nie in [30] considered the Carleman estimate and null controllability of a cascade control system with convection terms. For degenerate equations, one must overcome some technical difficulties to get some necessary estimates for controllability theory. In particular, the following system governed by a single degenerate parabolic equation has been widely studied:

$$
\begin{aligned}
& w_{t}-\left(x^{\alpha} w_{x}\right)_{x}+k(x, t) w=h(x, t) \chi_{\omega}, \quad(x, t) \in Q_{T}, \\
& w(0, t)=0 \quad \text { if } 0<\alpha<1, \quad\left(x^{\alpha} w_{x}\right)(0, t)=0 \quad \text { if } \alpha \geq 1, t \in(0, T), \\
& w(1, t)=0, \quad t \in(0, T), \\
& w(x, 0)=w_{0}(x), \quad x \in(0,1),
\end{aligned}
$$

where $k \in L^{\infty}\left(Q_{T}\right)$. The system is null controllable if $0<\alpha<2[8,9,26]$, while not if $\alpha \geq 2$ [7]. It is noted that the degeneracy of (1.6) is weak if $0<\alpha<1$ and strong if $\alpha \geq 1$. The null controllability of system (1.6)-(1.9) for $0<\alpha<2$ is based on the Carleman estimate for solutions to its conjugate problem

$$
\begin{aligned}
& -W_{t}-\left(x^{\alpha} W_{x}\right)_{x}+k(x, t) W=F(x, t), \quad(x, t) \in Q_{T}, \\
& W(0, t)=0 \quad \text { if } 0<\alpha<1, \quad\left(x^{\alpha} W_{x}\right)(0, t)=0 \quad \text { if } 1 \leq \alpha<2, t \in(0, T), \\
& W(1, t)=0, \quad t \in(0, T), \\
& W(x, T)=W_{T}(x), \quad x \in(0,1) .
\end{aligned}
$$

Since the problem may be not null controllable, the authors introduced some new concepts on controllability, the regional null controllability and the persistent regional null controllability, which is weaker than the null controllability [7]. They proved that the problem is regional null controllable and persistent regional null controllable for all $\alpha>0$. For semilinear problem (1.1)-(1.4), the authors also showed the regional and persistent regional null controllability in $[3,5]$. Moreover, the approximate controllability of degenerate equation (1.1) with suitable boundary and initial conditions has been proved in [12, 2729] for all $\alpha>0$. In [1, 19], the authors proved the null controllability of problem (1.1)-(1.4) with

$$
g\left(x, t, u, u_{x}\right)=f(x, t, u)
$$

and

$$
g\left(x, t, u, u_{x}\right)=x^{\alpha / 2} b(x, t) u_{x}+c(x, t) u,
$$

respectively. 
In this paper, we investigate the null controllability of semilinear problem (1.1)-(1.4). First, we prove the approximate null controllability of linear problem (1.1)-(1.4) with (1.14). Next, we prove the approximate null controllability of semilinear problem (1.1)(1.4) by using the Schauder fixed point theorem. At last, we state the null controllability of semilinear problem (1.1)-(1.4) with the method inspired by [3]. The paper is organized as follows: In Sect. 2, we introduce function spaces that are needed for the well-posedness and prove the well-posedness of system (1.1)-(1.4). In Sect. 3, we prove that the semilinear system is null controllable.

\section{Well-posedness}

In this section, we first consider the linear problem

$$
\begin{aligned}
& u_{t}-\left(x^{\alpha} u_{x}\right)_{x}+x^{\alpha / 2} b(x, t) u_{x}+c(x, t) u=f(x, t), \quad(x, t) \in Q_{T}, \\
& u(0, t)=u(1, t)=0 \quad \text { if } 0<\alpha<1, t \in(0, T), \\
& x^{\alpha} u_{x}(0, t)=u(1, t)=0 \quad \text { if } 1 \leq \alpha<2, t \in(0, T), \\
& u(x, 0)=u_{0}(x), \quad x \in(0,1),
\end{aligned}
$$

where $b, c \in L^{\infty}\left(Q_{T}\right), f \in L^{2}\left(Q_{T}\right)$, and $u_{0} \in L^{2}(0,1)$.

Define that $H_{\alpha}^{1}(0,1)$ and $H_{\alpha}^{2}(0,1)$ are the closure of $C_{0}^{\infty}(0,1)$ with respect to the following norm:

$$
\|u\|_{H_{\alpha}^{1}(0,1)}=\left(\int_{0}^{1}\left(u^{2}+x^{\alpha} u_{x}^{2}\right) d x\right)^{1 / 2}, \quad u \in H_{\alpha}^{1}(0,1)
$$

and

$$
\|u\|_{H_{\alpha}^{2}(0,1)}=\left(\int_{0}^{1}\left(u^{2}+x^{\alpha} u_{x}^{2}+\left(x^{\alpha} u_{x}\right)_{x}^{2}\right) d x\right)^{1 / 2}, \quad u \in H_{\alpha}^{2}(0,1)
$$

respectively.

For readers' convenience, we denote

$$
\mathcal{M}=C\left(0, T ; L^{2}(0,1)\right) \cap L^{2}\left(0, T ; H_{\alpha}^{1}(0,1)\right)
$$

and

$$
\mathcal{N}=H^{1}\left(0, T ; L^{2}(0,1)\right) \cap L^{2}\left(0, T ; H_{\alpha}^{2}(0,1)\right) .
$$

Lemma 2.1 $\mathcal{N}$ is compactly imbedded in $\mathcal{M}$.

Proof Using Aubin's theorem ([3], Theorem 4.3) with $r_{0}=r_{1}=2, X_{0}=H_{\alpha}^{2}(0,1), X_{1}=$ $H_{\alpha}^{1}(0,1), X_{2}=L^{2}(0,1)$, and $a=0, b=T$, one can get that $\mathcal{N}$ is compactly imbedded in $L^{2}\left(0, T ; H_{\alpha}^{1}(0,1)\right)$.

Since $H^{1}\left(0, T ; L^{2}(0,1)\right)$ is compactly imbedded in $C\left(0, T ; L^{2}(0,1)\right)$ and $\mathcal{N}$ is continuously imbedded in $H^{1}\left(0, T ; L^{2}(0,1)\right)$, one has that $\mathcal{N}$ is compactly imbedded in $C\left(0, T ; L^{2}(0,1)\right)$. 
Moreover, since $\mathcal{N}$ is compactly imbedded in $L^{2}\left(0, T ; H_{\alpha}^{1}(0,1)\right)$ and $C\left(0, T ; L^{2}(0,1)\right)$, respectively, it is obvious that $\mathcal{N}$ is compactly imbedded in $\mathcal{M}=C\left(0, T ; L^{2}(0,1)\right) \cap$ $L^{2}\left(0, T ; H_{\alpha}^{1}(0,1)\right)$, the proof is complete.

Due to the degeneracy of the coefficient $x^{\alpha}$, problem (2.1)-(2.4) may not have classical solutions, so we need to give the definition of weak solutions.

Definition 2.1 If $u \in \mathcal{M}$, for any function $\varphi \in \mathcal{M}$ with $\varphi_{t} \in L^{2}\left(Q_{T}\right)$ and $\left.\varphi(\cdot, T)\right|_{(0,1)}=0$, it holds that

$$
\iint_{Q_{T}}\left(-u \varphi_{t}+x^{\alpha} u_{x} \varphi_{x}+x^{\alpha / 2} b u_{x} \varphi+c u \varphi\right) d x d t=\iint_{Q_{T}} f \varphi d x d t+\int_{0}^{1} u_{0}(x) \varphi(x, 0) d x,
$$

then the function $u$ is called the weak solution of the system (2.1)-(2.4).

On the basis of Theorem 2.4 [3] and Lemma 2.1 [12], the problem (2.1)-(2.4) is well posed. Furthermore, we can get the following proposition.

Proposition 2.1 If $\|b\|_{L^{\infty}\left(Q_{T}\right)} \leq C_{1},\|c\|_{L^{\infty}\left(Q_{T}\right)} \leq C_{2}, f \in L^{2}\left(Q_{T}\right)$, and $u_{0} \in L^{2}(0,1)$, then the problem (2.1)-(2.4) uniquely admits a weak solution $u \in \mathcal{M}$. Furthermore, u satisfies that

(i)

$$
\sup _{t \in(0, T]} \int_{0}^{1} u^{2}(x, t) d x+\iint_{Q_{T}} x^{\alpha} u_{x}^{2} d x d t \leq C\left(\iint_{Q_{T}} f^{2}(x, t) d x d t+\int_{0}^{1} u_{0}^{2}(x) d x\right)
$$

where $C>0$ is a constant depending on $T, C_{1}$, and $C_{2}$.

(ii) If $u_{0} \in H_{\alpha}^{1}(0,1)$, then $u \in \mathcal{N}$ and it holds that

$$
\begin{aligned}
& \iint_{Q_{T}}\left(u_{t}^{2}+\left(x^{\alpha} u_{x}\right)_{x}^{2}\right) d x d t \\
& \quad \leq C\left(\iint_{Q_{T}} f^{2}(x, t) d x d t+\int_{0}^{1}\left(u_{0}^{2}(x)+x^{\alpha}\left(u_{0}^{\prime}\right)^{2}(x)\right) d x\right),
\end{aligned}
$$

where $C>0$ is a constant depending on $T, C_{1}$, and $C_{2}$.

Similar to the linear problem (2.1)-(2.4), one can give the definition of weak solution to the following semilinear problem:

$$
\begin{aligned}
& u_{t}-\left(x^{\alpha} u_{x}\right)_{x}+g\left(x, t, u, u_{x}\right)=f(x, t), \quad(x, t) \in Q_{T}, \\
& u(0, t)=u(1, t)=0 \quad \text { if } 0<\alpha<1, t \in(0, T), \\
& x^{\alpha} u_{x}(0, t)=u(1, t)=0 \quad \text { if } 1 \leq \alpha<2, t \in(0, T), \\
& u(x, 0)=u_{0}(x), \quad x \in(0,1) .
\end{aligned}
$$

Definition 2.2 A function $u$ is called the weak solution of the problem (2.5)-(2.8) if $u \in$ $\mathcal{M}$, and for any function $\varphi \in \mathcal{M}$ with $\varphi_{t} \in L^{2}\left(Q_{T}\right)$ and $\left.\varphi(\cdot, T)\right|_{(0,1)}=0$, the following integral equality holds:

$$
\iint_{Q_{T}}\left(-u \varphi_{t}+x^{\alpha} u_{x} \varphi_{x}+g\left(x, t, u, u_{x}\right) \varphi\right) d x d t=\iint_{Q_{T}} f \varphi d x d t+\int_{0}^{1} u_{0}(x) \varphi(x, 0) d x
$$


The semilinear problem (2.5)-(2.8) is well posed, which is proved in Theorem 3.1 [12] and Theorem 3.7 [3].

For any $w \in L^{2}\left(0, T ; H_{\alpha}^{1}(0,1)\right)$, define the functions

$$
\begin{aligned}
& c(x, t, w)=\int_{0}^{1} g_{s}\left(x, t, \lambda w, \lambda w_{x}\right) d \lambda, \\
& b(x, t, w)=x^{-\alpha / 2} \int_{0}^{1} g_{p}\left(x, t, \lambda w, \lambda w_{x}\right) d \lambda .
\end{aligned}
$$

Then (1.5) yields that

$$
\|c(x, t, w)\|_{L^{\infty}\left(Q_{T} \times \mathbb{R}\right)} \leq K,\|b(x, t, w)\|_{L^{\infty}\left(Q_{T} \times \mathbb{R}\right)} \leq K .
$$

Moreover, we can obtain that

$$
\begin{aligned}
g\left(x, t, u, u_{x}\right)-g(x, t, 0,0) & =\int_{0}^{1} \frac{\partial g\left(x, t, \lambda u, \lambda u_{x}\right)}{\partial \lambda} d \lambda \\
& =\int_{0}^{1} \frac{\partial g\left(x, t, \lambda u, \lambda u_{x}\right)}{\partial s} u d \lambda+\int_{0}^{1} \frac{\partial g\left(x, t, \lambda u, \lambda u_{x}\right)}{\partial p} u_{x} d \lambda \\
& =c(x, t, u) u+x^{\alpha / 2} b(x, t, u) u_{x} .
\end{aligned}
$$

Furthermore, $c(x, t, w)$ and $b(x, t, w)$ satisfy the following property.

Lemma 2.2 Assume that $\left\{w_{k}\right\}_{k=1}^{\infty}$ converges to $w$ in $L^{2}\left(0, T ; H_{\alpha}^{1}(0,1)\right)$, then

$$
\begin{aligned}
& c\left(x, t, w_{k}(x, t)\right) \rightarrow c(x, t, w(x, t)) \text { weakly } * \text { in } L^{\infty}\left(Q_{T}\right), \quad \text { as } k \rightarrow \infty, \\
& b\left(x, t, w_{k}(x, t)\right) \rightarrow b(x, t, w(x, t)) \text { weakly } * \text { in } L^{\infty}\left(Q_{T}\right), \quad \text { as } k \rightarrow \infty
\end{aligned}
$$

and

$$
\begin{aligned}
& \left(c \left(x, t, w_{k}(x, t)-c(x, t, w(x, t))^{2} \rightarrow 0 \text { weakly } * \text { in } L^{\infty}\left(Q_{T}\right), \quad \text { as } k \rightarrow \infty,\right.\right. \\
& \left(b \left(x, t, w_{k}(x, t)-b(x, t, w(x, t))^{2} \rightarrow 0 \text { weakly } * \text { in } L^{\infty}\left(Q_{T}\right), \quad \text { as } k \rightarrow \infty .\right.\right.
\end{aligned}
$$

Proof For convenience, we denote

$$
c[w](x, t)=c(x, t, w(x, t)), \quad b[w](x, t)=b(x, t, w(x, t)), \quad w \in L^{2}\left(0, T ; H_{\alpha}^{1}(0,1)\right) .
$$

First, we will prove

$$
\lim _{k \rightarrow \infty} \iint_{Q_{T}}\left|c\left[w_{k}\right](x, t)-c[w](x, t)\right| d x d t=0
$$

For each $\delta>0$, let

$$
E_{\delta}=\left\{(x, t) \in Q_{T}: x^{\alpha} \leq \delta\right\}, \quad F_{\delta}=\left\{(x, t) \in Q_{T}: x^{\alpha}>\delta\right\}
$$


Combined $\lim _{\delta \rightarrow 0}$ meas $E_{\delta}=0$ with (2.9), we only need to prove

$$
\lim _{k \rightarrow \infty} \iint_{F_{\delta}}\left|c\left[w_{k}\right](x, t)-c[w](x, t)\right| d x d t=0, \quad \delta>0
$$

Fix $\delta>0$, since $\left\{w_{k}\right\}_{k=1}^{\infty}$ converges to $w$ in $L^{2}\left(0, T ; H_{\alpha}^{1}(0,1)\right)$, then

$$
\lim _{k \rightarrow \infty} \iint_{F_{\delta}}\left(w_{k}-w\right)^{2} d x d t=0, \quad \lim _{k \rightarrow \infty} \iint_{F_{\delta}}\left(w_{k x}-w_{x}\right)^{2} d x d t=0
$$

For any integers $m, j>0$, denote

$$
F_{\delta, m}=\left\{(x, t) \in F_{\delta},|w(x, t)|+\left|w_{x}(x, t)\right|>m\right\}
$$

and

$$
F_{\delta, m, j}=\left\{(x, t) \in F_{\delta}: \text { there exsits } k \geq j \text {, such that }\left|w_{k}(x, t)\right|+\left|w_{k x}(x, t)\right|>m+1\right\},
$$

then

$$
\lim _{m \rightarrow \infty} \operatorname{meas} F_{\delta, m}=0
$$

Furthermore, (2.16) shows that

$$
\lim _{j \rightarrow \infty} \operatorname{meas}\left(F_{\delta, m, j} \backslash F_{\delta, m}\right)=0, \quad m=1,2, \cdots
$$

It follows from the definition of $c[w](x, t)$ and (2.9) that

$$
\begin{aligned}
& \iint_{F_{\delta}}\left|c\left[w_{k}\right](x, t)-c[w](x, t)\right| d x d t \\
& =\iint_{F_{\delta} \backslash\left(F_{\delta, m} \cup F_{\delta, m, j}\right)}\left|c\left[w_{k}\right](x, t)-c[w](x, t)\right| d x d t+\iint_{F_{\delta, m}}\left|c\left[w_{k}\right](x, t)-c[w](x, t)\right| d x d t \\
& \quad+\iint_{F_{\delta, m, j} \backslash F_{\delta, m}}\left|c\left[w_{k}\right](x, t)-c[w](x, t)\right| d x d t \\
& \quad \iint_{F_{\delta} \backslash\left(F_{\delta, m} \cup F_{\delta, m, j}\right)}\left|c\left[w_{k}\right](x, t)-c[w](x, t)\right| d x d t \\
& \quad+2 K \text { meas } F_{\delta, m}+2 K \operatorname{meas}\left(F_{\delta, m, j} \backslash F_{\delta, m}\right) .
\end{aligned}
$$

Since $g(x, t, s, p)$ is $C^{1}$ continuous with respect to $s, p$ uniformly for $(x, t) \in Q_{T}$, then

$$
\begin{aligned}
& \lim _{k \rightarrow \infty} \iint_{F_{\delta} \backslash\left(F_{\delta, m} \cup F_{\delta, m, j}\right)}\left|\frac{\partial g}{\partial s}\left(x, t, \lambda w_{k}, \lambda w_{k x}\right)-\frac{\partial g}{\partial s}\left(x, t, \lambda w, \lambda w_{x}\right) d \lambda\right| d x d t=0, \\
& m, j=1,2, \cdots
\end{aligned}
$$

Let $k \rightarrow \infty, j \rightarrow \infty, m \rightarrow \infty$ in turn in (2.19), one can deduce (2.15) from (2.17), (2.18), (2.20), and thus (2.14) holds. 
Fix $\varphi(x, t) \in L^{1}\left(Q_{T}\right)$, for any integer $n>0$, we can deduce from (2.9) that

$$
\begin{aligned}
& \iint_{Q_{T}}\left(c\left[w_{k}\right](x, t)-c[w](x, t)\right) \varphi(x, t) d x d t \\
& =\iint_{\left\{(x, t) \in Q_{T}:|\varphi(x, t)|>n\right\}}\left(c\left[w_{k}\right]-c[w]\right) \varphi(x, t) d x d t \\
& \quad+\iint_{\left\{(x, t) \in Q_{T}:|\varphi(x, t)| \leq n\right\}}\left(c\left[w_{k}\right]-c[w]\right) \varphi(x, t) d x d t \\
& \leq 2 K \iint_{\left\{(x, t) \in Q_{T}:|\varphi(x, t)|>n\right\}}|\varphi(x, t)| d x d t \\
& \quad+n \iint_{\left\{(x, t) \in Q_{T}:|\varphi(x, t)| \leq n\right\}}\left|c\left[w_{k}\right](x, t)-c[w](x, t)\right| d x d t
\end{aligned}
$$

and

$$
\begin{aligned}
& \iint_{Q_{T}}\left(c\left[w_{k}\right](x, t)-c[w](x, t)\right)^{2} \varphi(x, t) d x d t \\
& =\iint_{\left\{(x, t) \in Q_{T}:|\varphi(x, t)|>n\right\}}\left(c\left[w_{k}\right]-c[w]\right)^{2} \varphi(x, t) d x d t \\
& \quad+\iint_{\left\{(x, t) \in Q_{T}:|\varphi(x, t)| \leq n\right\}}\left(c\left[w_{k}\right]-c[w]\right)^{2} \varphi(x, t) d x d t \\
& \leq 4 K^{2} \iint_{\left\{(x, t) \in Q_{T}:|\varphi(x, t)|>n\right\}}|\varphi(x, t)| d x d t \\
& \quad+2 n K \iint_{\left\{(x, t) \in Q_{T}:|\varphi(x, t)| \leq n\right\}}\left|c\left[w_{k}\right](x, t)-c[w](x, t)\right| d x d t .
\end{aligned}
$$

Let $k \rightarrow \infty$ and then $n \rightarrow \infty$ in (2.21) and (2.22), it follows from $\varphi \in L^{1}\left(Q_{T}\right)$ and (2.14) that

$$
\lim _{k \rightarrow \infty} \iint_{Q_{T}}\left(c\left[w_{k}\right](x, t)-c[w](x, t)\right) \varphi(x, t) d x d t=0
$$

and

$$
\lim _{k \rightarrow \infty} \iint_{Q_{T}}\left(c\left[w_{k}\right](x, t)-c[w](x, t)\right)^{2} \varphi(x, t) d x d t=0 .
$$

The convergence for $b[w](x, t)$ can be proved similarly, the proof is complete.

Theorem 2.1 For any $f \in L^{2}\left(Q_{T}\right)$ and $u_{0} \in L^{2}(0,1)$, the problem (2.5)-(2.8) has a unique weak solution.

Proof We divide the proof into two steps.

Step 1. Let us prove the existence of the weak solution to the problem by using the Schauder fixed point theorem. It follows from Proposition 2.1 that the problem

$$
\begin{aligned}
& u_{t}-\left(x^{\alpha} u_{x}\right)_{x}+x^{\alpha / 2} b(x, t, w) u_{x}+c(x, t, w) u=f(x, t)-g(x, t, 0,0), \quad(x, t) \in Q_{T}, \\
& u(0, t)=u(1, t)=0 \quad \text { if } 0<\alpha<1, t \in(0, T),
\end{aligned}
$$




$$
\begin{aligned}
& x^{\alpha / 2} u_{x}(0, t)=u(1, t)=0 \quad \text { if } 1 \leq \alpha<2, t \in(0, T), \\
& u(x, 0)=0, \quad x \in(0,1)
\end{aligned}
$$

admits a unique weak solution. Define an operator $\Lambda$ :

$$
\Lambda(w)=u, \quad w \in L^{2}\left(0, T ; H_{\alpha}^{1}(0,1)\right)
$$

where $u$ is the weak solution to problem (2.23)-(2.26). For any $\left\{w_{k}\right\}_{k=1}^{\infty} \subset L^{2}\left(0, T ; H_{\alpha}^{1}(0,1)\right)$, it follows from (1.5) that $\left\{c\left(x, t, w_{k}\right)\right\}_{k=1}^{\infty}$ and $\left\{b\left(x, t, w_{k}\right)\right\}_{k=1}^{\infty}$ are uniformly bounded in $L^{\infty}\left(Q_{T}\right)$, respectively. Therefore, there exists a subsequence of the integer set $k$, denoted by itself for convenience, such that $\left\{c\left(x, t, w_{k}\right)\right\}_{k=1}^{\infty}$ and $\left\{b\left(x, t, w_{k}\right)\right\}_{k=1}^{\infty}$ converge weakly $*$ in $L^{\infty}\left(Q_{T}\right)$, respectively. Then, it is deduced from Corollary 2.3 in [12] that there exists a subsequence of $\left\{\Lambda\left(w_{k}\right)\right\}_{k=1}^{\infty}$, which converges in $L^{2}\left(0, T ; H_{\alpha}^{1}(0,1)\right)$, hence $\Lambda$ is precompact.

Now we assume that $\left\{w_{k}\right\}_{k=1}^{\infty}$ converges to $w$ in $L^{2}\left(0, T ; H_{\alpha}^{1}(0,1)\right)$, it follows from Lemma 2.2 that

$$
\begin{aligned}
& \left(c\left(x, t, w_{k}(x, t)\right)-c(x, t, w(x, t))\right)^{2} \rightarrow 0 \text { weakly } * \text { in } L^{\infty}\left(Q_{T}\right), \\
& \left(b\left(x, t, w_{k}(x, t)\right)-b(x, t, w(x, t))\right)^{2} \rightarrow 0 \text { weakly } * \text { in } L^{\infty}\left(Q_{T}\right) .
\end{aligned}
$$

From the convergence above and Corollary 2.4 in [12], $\Lambda\left(w_{k}\right)$ converges to $\Lambda(w)$ in $L^{2}\left(0, T ; H_{\alpha}^{1}(0,1)\right)$, therefore $\Lambda$ is continuous.

According to the discussion above, we know that $\Lambda$ is precompact and continuous on the closed and convex hull of its range, then $\Lambda$ satisfies the hypotheses of the Schauder fixed point theorem. Therefore, there exists a function $u \in L^{2}\left(0, T ; H_{\alpha}^{1}(0,1)\right)$ such that $u=$ $\Lambda(u) \in \mathcal{M}$ is the weak solution to the problem (2.5)-(2.8).

Step 2. Let us prove the uniqueness of the weak solution. Assume that $u$ and $v$ are two weak solutions to the problem (2.5)-(2.8) and set

$$
w(x, t)=u(x, t)-v(x, t), \quad(x, t) \in Q_{T} .
$$

Note that

$$
\begin{aligned}
g\left(x, t, u, u_{x}\right)-g\left(x, t, v, v_{x}\right)= & \int_{0}^{1} \frac{\partial}{\partial \lambda} g\left(x, t, \lambda u+(1-\lambda) v, \lambda u_{x}+(1-\lambda) v_{x}\right) d \lambda \\
= & \int_{0}^{1}(u-v) \frac{\partial}{\partial s} g\left(x, t, \lambda u+(1-\lambda) v, \lambda u_{x}+(1-\lambda) v_{x}\right) d \lambda \\
& +\int_{0}^{1}(u-v)_{x} \frac{\partial}{\partial p} g\left(x, t, \lambda u+(1-\lambda) v, \lambda u_{x}+(1-\lambda) v_{x}\right) d \lambda \\
= & w \int_{0}^{1} \frac{\partial}{\partial s} g\left(x, t, \lambda u+(1-\lambda) v, \lambda u_{x}+(1-\lambda) v_{x}\right) d \lambda \\
& +w_{x} \int_{0}^{1} \frac{\partial}{\partial p} g\left(x, t, \lambda u+(1-\lambda) v, \lambda u_{x}+(1-\lambda) v_{x}\right) d \lambda \\
= & \theta(x, t) w+x^{\alpha / 2} \psi(x, t) w_{x}, \quad(x, t) \in Q_{T},
\end{aligned}
$$


where

$$
\begin{aligned}
& \theta(x, t)=\int_{0}^{1} \frac{\partial}{\partial s} g\left(x, t, \lambda u+(1-\lambda) v, \lambda u_{x}+(1-\lambda) v_{x}\right) d \lambda \\
& \psi(x, t)=x^{-\alpha / 2} \int_{0}^{1} \frac{\partial}{\partial p} g\left(x, t, \lambda u+(1-\lambda) v, \lambda u_{x}+(1-\lambda) v_{x}\right) d \lambda .
\end{aligned}
$$

Then $w(x, t)$ is the solution to the following problem:

$$
\begin{aligned}
& w_{t}-\left(x^{\alpha} w_{x}\right)_{x}+\theta(x, t) w+x^{\alpha / 2} \psi(x, t) w_{x}=0, \quad(x, t) \in Q_{T}, \\
& w(0, t)=w(1, t)=0 \quad \text { if } 0<\alpha<1, t \in(0, T), \\
& x^{\alpha} w_{x}(0, t)=w(1, t)=0 \quad \text { if } 1 \leq \alpha<2, t \in(0, T), \\
& w(x, 0)=0, \quad x \in(0,1) .
\end{aligned}
$$

It follows from Proposition 2.1 that

$$
w(x, t)=0, \quad(x, t) \in Q_{T},
$$

which yields

$$
u(x, t)=v(x, t), \quad(x, t) \in Q_{T} .
$$

The proof is complete.

\section{Null controllability}

In this section, we first consider the approximate null controllability of the linear problem

$$
\begin{aligned}
& u_{t}-\left(x^{\alpha} u_{x}\right)_{x}+x^{\alpha / 2} b(x, t) u_{x}+c(x, t) u=h(x, t) \chi_{\omega}, \quad(x, t) \in Q_{T}, \\
& u(0, t)=u(1, t)=0 \quad \text { if } 0<\alpha<1, t \in(0, T), \\
& x^{\alpha} u_{x}(0, t)=u(1, t)=0 \quad \text { if } 1 \leq \alpha<2, t \in(0, T), \\
& u(x, 0)=u_{0}(x), \quad x \in(0,1)
\end{aligned}
$$

where $b, c \in L^{\infty}\left(Q_{T}\right), h \in L^{2}\left(Q_{T}\right)$, and $u_{0} \in H_{\alpha}^{1}(0,1)$.

Theorem 3.1 The problem (3.1)-(3.4) is approximately null controllable, which means that, for any $\varepsilon>0$, there exists a function $h_{\varepsilon} \in L^{2}\left(Q_{T}\right)$ such that

$$
\int_{0}^{T} \int_{\omega} h_{\varepsilon}^{2} d x d t \leq C \int_{0}^{1} u_{0}^{2}(x) d x, \quad\left\|u_{\varepsilon}(x, T)\right\|_{L^{2}(0,1)} \leq \varepsilon
$$

where $C>0$ is a constant independent of $\varepsilon$ and $u_{\varepsilon}$ is the solution of (3.1)-(3.4) with $h=h_{\varepsilon}$.

Proof Define a functional

$$
J_{\varepsilon}(h)=\frac{1}{2} \int_{0}^{T} \int_{\omega} h^{2} d x d t+\frac{1}{2 \varepsilon} \int_{0}^{1} u^{2}(x, T) d x, \quad h \in L^{2}\left(Q_{T}\right),
$$


where $u$ is the solution to problem (3.1)-(3.4). It is not hard to prove that the functional has a unique minimum point

$$
h_{\varepsilon}=-\varphi_{\varepsilon} \chi_{\omega},
$$

where $\varphi_{\varepsilon}$ is the solution to the conjugate problem

$$
\begin{aligned}
& \left(\varphi_{\varepsilon}\right)_{t}+\left(x^{\alpha}\left(\varphi_{\varepsilon}\right)_{x}\right)_{x}+\left(x^{\alpha / 2} b \varphi_{\varepsilon}\right)_{x}-c \varphi=0, \quad(x, t) \in Q_{T}, \\
& \varphi_{\varepsilon}(0, t)=\varphi_{\varepsilon}(1, t)=0 \quad \text { if } 0<\alpha<1, t \in(0, T), \\
& x^{\alpha}\left(\varphi_{\varepsilon}\right)_{x}(0, t)=\varphi_{\varepsilon}(1, t)=0 \quad \text { if } 1 \leq \alpha<2, t \in(0, T), \\
& \varphi_{\varepsilon}(x, T)=\frac{1}{\varepsilon} u_{\varepsilon}(x, T), \quad x \in(0,1) .
\end{aligned}
$$

Multiplying (3.7) by $u_{\varepsilon}$ and then integrating by parts, one can get that

$$
\begin{aligned}
& \int_{0}^{1} u_{\varepsilon}(x, T) \varphi_{\varepsilon}(x, T) d x-\int_{0}^{1} u_{0}(x) \varphi_{\varepsilon}(x, 0) d x \\
& \quad=\iint_{Q_{T}}\left(\left(u_{\varepsilon}\right)_{t}-\left(x^{\alpha}\left(u_{\varepsilon}\right)_{x}\right)_{x}+x^{\alpha / 2} b(x, t)\left(u_{\varepsilon}\right)_{x}+c(x, t) u_{\varepsilon}\right) \varphi_{\varepsilon} d x d t \\
& \quad=\int_{0}^{T} \int_{\omega} h_{\varepsilon} \varphi_{\varepsilon} d x d t
\end{aligned}
$$

A combination of (3.6), (3.10) and (3.11) implies that

$$
\int_{0}^{T} \int_{\omega} h_{\varepsilon}^{2} d x d t+\frac{1}{\varepsilon} \int_{0}^{1} u_{\varepsilon}^{2}(x, T) d x=\int_{0}^{1} u_{0}(x) \varphi_{\varepsilon}(x, 0) d x
$$

As shown in Lemma 3.1 [19], there exists a constant $C$ such that

$$
\int_{0}^{1} \varphi_{\varepsilon}^{2}(x, 0) d x \leq C \int_{0}^{T} \int_{\omega}\left(\varphi_{\varepsilon}\right)^{2}(x, t) d x d t
$$

Using Hölder's inequality with (3.12) and (3.13), one has

$$
\begin{aligned}
\int_{0}^{T} \int_{\omega} h_{\varepsilon}^{2} & \leq \int_{0}^{1} u_{0}(x) \varphi_{\varepsilon}(x, 0) d x \\
& \leq\left(\int_{0}^{1} u_{0}^{2}(x) d x\right)^{1 / 2}\left(\int_{0}^{1} \varphi_{\varepsilon}^{2}(x, 0) d x\right)^{1 / 2} \\
& \leq\left(\int_{0}^{1} u_{0}^{2}(x) d x\right)^{1 / 2}\left(C \int_{0}^{T} \int_{\omega} \varphi_{\varepsilon}^{2}(x, t) d x d t\right)^{1 / 2} \\
& \leq C^{1 / 2}\left(\int_{0}^{1} u_{0}^{2}(x) d x\right)^{1 / 2}\left(\int_{0}^{T} \int_{\omega} h_{\varepsilon}^{2}(x, t) d x d t\right)^{1 / 2}
\end{aligned}
$$


and

$$
\begin{aligned}
\int_{0}^{1} u_{\varepsilon}^{2}(x, T) d x & \leq \varepsilon \int_{0}^{1} u_{0}(x) \varphi_{\varepsilon}(x, 0) d x \\
& \leq \varepsilon\left(\int_{0}^{1} u_{0}^{2}(x) d x\right)^{1 / 2}\left(\int_{0}^{1} \varphi_{\varepsilon}^{2}(x, 0) d x\right)^{1 / 2} \\
& \leq \varepsilon\left(\int_{0}^{1} u_{0}^{2}(x) d x\right)^{1 / 2}\left(C \int_{0}^{T} \int_{\omega} h_{\varepsilon}^{2} d x\right)^{1 / 2},
\end{aligned}
$$

thus (3.5) holds and the proof is complete.

Theorem 3.2 If $u_{0} \in H_{\alpha}^{1}(0,1)$, then the semilinear system (1.1)-(1.4) is approximately null controllable, it means that, for any $\varepsilon>0$, there exists a control function $h_{\varepsilon} \in L^{2}\left(Q_{T}\right)$ such that

$$
\int_{0}^{T} \int_{\omega} h_{\varepsilon}^{2} d x d t \leq C \int_{0}^{1} u_{0}^{2}(x) d x, \quad\left\|u_{\varepsilon}(x, T)\right\|_{L^{2}(0,1)} \leq \varepsilon
$$

where $C>0$ is a constant independent of $\varepsilon$ and $u_{\varepsilon}$ is the solution of (1.1)-(1.4) with $h=h_{\varepsilon}$.

Proof For any $w \in \mathcal{M}$, we first consider the following problem:

$$
\begin{aligned}
& u_{t}-\left(x^{\alpha} u_{x}\right)_{x}+x^{\alpha / 2} b(x, t, w(x, t)) u_{x}+c(x, t, w(x, t)) u=h \chi_{\omega}, \quad(x, t) \in Q_{T}, \\
& u(0, t)=u(1, t)=0 \quad \text { if } 0<\alpha<1, t \in(0, T), \\
& x^{\alpha} u_{x}(0, t)=u(1, t)=0 \quad \text { if } 1 \leq \alpha<2, t \in(0, T), \\
& u(x, 0)=u_{0}(x), \quad x \in(0,1) .
\end{aligned}
$$

For any $h \in L^{2}\left(Q_{T}\right)$, we denote $u[w]$ to be the solution to the problem (3.15)-(3.18). Theorem 3.1 shows that, for any $\varepsilon>0$, there exists a function $h_{\varepsilon}[w]=\min _{h \in L^{2}\left(Q_{T}\right)} J_{\varepsilon}[w](h)$ such that

$$
\int_{0}^{T} \int_{\omega}\left(h_{\varepsilon}[w]\right)^{2} d x d t \leq C \int_{0}^{1} u_{0}^{2}(x) d x, \quad\left\|u_{\varepsilon}[w](x, T)\right\|_{L^{2}(0,1)} \leq \varepsilon
$$

where

$$
J_{\varepsilon}[w](h)=\frac{1}{2} \int_{0}^{T} \int_{\omega} h^{2} d x d t+\frac{1}{2 \varepsilon} \int_{0}^{1} u^{2}[w](x, T) d x, \quad h \in L^{2}\left(Q_{T}\right)
$$

and $u_{\varepsilon}[w]$ is the solution to problem (3.15)-(3.18) with $h=h_{\varepsilon}$. Define an operator as follows:

$$
\Gamma: w \in \mathcal{M} \mapsto u_{\varepsilon}[w] \in \mathcal{M} \text {. }
$$

It is easy to prove that $\Gamma$ is a bounded and compact operator from Proposition 2.1 and Lemma 2.1.

Now we will focus on proving the continuity of $\Gamma$. If $\left\{w_{k}\right\}_{k=1}^{\infty}$ converges to $w$ in $\mathcal{M}$, then we have (2.10) and (2.11) from Lemma 2.2. Since $h_{\varepsilon}\left[w_{k}\right]$ is bounded due to (3.19), then 
there exists a subsequence of $\left\{h_{\varepsilon}\left[w_{k}\right]\right\}_{k=1}^{\infty}$, denoted by itself for convenience, such that $\left\{h_{\varepsilon}\left[w_{k}\right]\right\}_{k=1}^{\infty}$ converges weakly to $\bar{h}_{\varepsilon}$ in $L^{2}\left(Q_{T}\right)$. Moreover, it follows from Proposition 2.1 and Lemma 2.1 that there exists a subsequence of $\left\{u_{\varepsilon}\left[w_{k}\right]\right\}_{k=1}^{\infty}$, denoted by itself for convenience, such that $\left\{u_{\varepsilon}\left[w_{k}\right]\right\}_{k=1}^{\infty}$ converges to $\bar{u}_{\varepsilon}$ in $\mathcal{M}$. Similarly, we can get that, for any $h \in L^{2}\left(Q_{T}\right),\left\{u\left[w_{k}\right]\right\}_{k=1}^{\infty}$ converges to $u[w]$ in $\mathcal{M}$. From Definition 2.1, we know that, for any function $\varphi \in \mathcal{M}$ with $\varphi_{t} \in L^{2}\left(Q_{T}\right)$ and $\left.\varphi(\cdot, T)\right|_{(0,1)}=0$, the following integral equality holds:

$$
\begin{aligned}
& \iint_{Q_{T}}\left(-u_{\varepsilon}\left[w_{k}\right] \varphi_{t}+x^{\alpha}\left(u_{\varepsilon}\left[w_{k}\right]\right)_{x} \varphi_{x}+x^{\alpha / 2} b\left(x, t, w_{k}\right)\left(u_{\varepsilon}\left[w_{k}\right]\right)_{x} \varphi\right. \\
& \left.\quad+c\left(x, t, w_{k}\right) u_{\varepsilon}\left[w_{k}\right] \varphi\right) d x d t \\
& =\iint_{Q_{T}} h_{\varepsilon}\left[w_{k}\right] \chi_{\omega} \varphi d x d t+\int_{0}^{1} u_{0}(x) \varphi(x, 0) d x .
\end{aligned}
$$

Letting $k \rightarrow \infty$ in (3.20), we have

$$
\begin{aligned}
& \iint_{Q_{T}}\left(-\bar{u}_{\varepsilon} \varphi_{t}+x^{\alpha}\left(\bar{u}_{\varepsilon}\right)_{x} \varphi_{x}+x^{\alpha / 2} b(x, t, w)\left(\bar{u}_{\varepsilon}\right)_{x} \varphi+c(x, t, w) \bar{u}_{\varepsilon} \varphi\right) d x d t \\
& \quad=\iint_{Q_{T}} \bar{h}_{\varepsilon} \chi_{\omega} \varphi d x d t+\int_{0}^{1} u_{0}(x) \varphi(x, 0) d x
\end{aligned}
$$

which means that $\bar{u}_{\varepsilon}$ is the weak solution to the problem (3.15)-(3.18) with $h=\bar{h}_{\varepsilon}$. To prove the continuity of $\Gamma$, we only need to prove $\bar{h}_{\varepsilon}=h_{\varepsilon}[w]$. Since $h_{\varepsilon}\left[w_{k}\right]$ is the minimum of $J_{\varepsilon}\left[w_{k}\right]$, then for all $h \in L^{2}\left(Q_{T}\right)$, it is obvious that

$$
\begin{gathered}
\frac{1}{2} \int_{0}^{T} \int_{\omega}\left(h_{\varepsilon}\left[w_{k}\right]\right)^{2} d x d t+\frac{1}{2 \varepsilon} \int_{0}^{1}\left(u_{\varepsilon}\left[w_{k}\right]\right)^{2}(x, T) d x \\
\quad \leq \frac{1}{2} \int_{0}^{T} \int_{\omega} h^{2} d x d t+\frac{1}{2 \varepsilon} \int_{0}^{1}\left(u\left[w_{k}\right]\right)^{2}(x, T) d x .
\end{gathered}
$$

Note that

$$
h_{\varepsilon}\left[w_{k}\right] \rightarrow \bar{h}_{\varepsilon} \text { in } L^{2}\left(Q_{T}\right), \quad u_{\varepsilon}\left[w_{k}\right] \rightarrow \bar{u}_{\varepsilon} \text { in } \mathcal{M}, \quad u\left[w_{k}\right] \rightarrow u[w] \text { in } \mathcal{M}, \quad \text { as } k \rightarrow \infty .
$$

Let $k \rightarrow \infty$ in (3.21), we obtain that

$$
\begin{aligned}
& \frac{1}{2} \int_{0}^{T} \int_{\omega}\left(\bar{h}_{\varepsilon}\right)^{2} d x d t+\frac{1}{2 \varepsilon} \int_{0}^{1}\left(\bar{u}_{\varepsilon}\right)^{2}(x, T) d x \\
& \quad \leq \frac{1}{2} \int_{0}^{T} \int_{\omega} h^{2} d x d t+\frac{1}{2 \varepsilon} \int_{0}^{1}(u[w])^{2}(x, T) d x .
\end{aligned}
$$

Thus, $\bar{h}_{\varepsilon}=h_{\varepsilon}[w]=\min _{h \in L^{2}\left(Q_{T}\right)} J_{\varepsilon}[w](h)$, so $\Gamma$ is continuous.

From the discussion above, one can get that $\Gamma$ satisfies the hypotheses of the Schauder fixed point theorem. Therefore, there exists a fixed point $u \in \mathcal{M}$ such that $\Gamma(u)=u$, it means that $u$ is the solution to problem (1.1)-(1.4) and satisfies (3.14). The proof is complete. 
Inspired by the proof of Theorem 3.6 and Theorem 3.8 in [3], one can prove the null controllability of system (1.1)-(1.4).

Theorem 3.3 The problem (1.1)-(1.4) is null controllable. More precisely, for any $u_{0} \in$ $L^{2}(0,1)$, there exists a control function $h \in L^{2}\left(Q_{T}\right)$ such that the solution $u$ to the problem (1.1)-(1.4) satisfies

$$
u(x, T)=0, \quad \text { a.e. } x \in(0,1) .
$$

\section{Acknowledgements}

The authors would like to thank the referees for their valuable comments and suggestions which improved the original manuscript.

\section{Funding}

This work is supported by the National Nature Science Foundation of China (No. 11601182, Yuanyuan Nie), by the National Nature Science Foundation of China (No. 11801211, Qian Zhou), by the Science and Technology Development Project of Jilin Province (20180520213JH, Yuanyuan Nie), and by the Scientific and Technological Project of Jilin Provinces's Education Department in Thirteenth-five-Year (JJKH20180114KJ, Yuanyuan Nie).

\section{Availability of data and materials}

No applicable.

\section{Competing interests}

The authors declare that they have no competing interests.

\section{Authors' contributions}

All the authors contributed to each part of this study equally, read and approved the final version of the manuscript

\section{Publisher's Note}

Springer Nature remains neutral with regard to jurisdictional claims in published maps and institutional affiliations.

Received: 9 November 2019 Accepted: 27 February 2020 Published online: 06 March 2020

\section{References}

1. Alabau-Boussouira, F., Cannarsa, P., Fragnelli, G.: Carleman estimates for degenerate parabolic operators with applications to null controllability. J. Evol. Equ. 6(2), 161-204 (2006)

2. Cannarasa, P., Tort, J., Yamamoto, M.: Unique continuation and approximate controllability for a degenerate parabolic equation. Appl. Anal. 91(8), 1409-1425 (2012)

3. Cannarsa, P., Fragnelli, G.: Null controllability of semilinear degenerate parabolic equations in bounded domains. Electron. J. Differ. Equ. 2006, Article ID 136 (2006)

4. Cannarsa, P., Fragnelli, G., Vancostenoble, J.: Linear degenerate parabolic equations in bounded domains: controllability and observability. In: Systems, Control, Modeling and Optimization. IFIP Int. Fed. Inf. Process., vol. 202, pp. 163-173. Springer, New York (2006)

5. Cannarsa, P., Fragnelli, G., Vancostenoble, J.: Regional controllability of semilinear degenerate parabolic equations in bounded domains. J. Math. Anal. Appl. 320(2), 804-818 (2006)

6. Cannarsa, P., Martinez, P., Vancostenoble, J.: Persistent regional null controllability for a class of degenerate parabolic equations. Commun. Pure Appl. Anal. 4, 607-635 (2004)

7. Cannarsa, P., Martinez, P., Vancostenoble, J.: Persistent regional controllability for a class of degenerate parabolic equations. Commun. Pure Appl. Anal. 3(4), 607-635 (2004)

8. Cannarsa, P., Martinez, P., Vancostenoble, J.: Null controllability of degenerate heat equations. Adv. Differ. Equ. 2, 153-190 (2005)

9. Cannarsa, P., Martinez, P., Vancostenoble, J.: Carleman estimates for a class of degenerate parabolic operators. SIAM J. Control Optim. 47(1), 1-19 (2008)

10. Du, R.: Approximate controllability of a class of semilinear degenerate systems with boundary control. J. Differ. Equ. 256, 3141-3165 (2014)

11. Du, R., Wang, C.: Null controllability of a class of systems governed by coupled degenerate equations. Appl. Math. Lett. 26(1), 113-119 (2013)

12. Du, R., Wang, C., Zhou, Q.: Approximate controllability of a semilinear system involving a fully nonlinear gradient term. Appl. Math. Optim. 70, 165-183 (2014)

13. Du, R., Xu, F.: On the boundary controllability of a semilinear degenerate system with the convection term. Appl. Math. Comput. 303, 113-127 (2017)

14. Du, R., Xu, F.: Null controllability of a coupled degenerate system with the first order terms. J. Dyn. Control Syst. 24 83-92 (2018)

15. Fabre, C.: Uniqueness results for Stokes equations and their consequences in linear and nonlinear control problems. ESAIM Control Optim. Calc. Var. 1, 267-302 (1996) 
16. Fabre, C., Puel, J., Zuazua, E.: Approximate controllability of a semilinear heat equation. Proc. R. Soc. Edinb., Sect. A 125(1), 31-61 (1995)

17. Fernández-Cara, E., Zuazua, E.: The cost of approximate controllability for heat equations: the linear case. Adv. Differ. Equ. 5, 465-514 (2000)

18. Fernández-Cara, E., Zuazua, E.: Null and approximate controllability for weakly blowing up semilinear heat equations. Ann. Inst. Henri Poincaré, Anal. Non Linéaire 17(5), 583-616 (2000)

19. Flores, C., Teresa, L.: Carleman estimates for degenerate parabolic equations with first order terms and applications. C. R. Acad. Sci. Paris, Ser. I 348, 391-396 (2010)

20. Fursikov, A.V., Imanuvilov, O.Y.: Controllability of Evolution Equations. Lecture Notes Series, vol. 34. Seoul National University, Seoul (1996)

21. Gao, H., Hou, X., Pavel, N.H.: Optimal control and controllability problems for a class of nonlinear degenerate diffusion equations. Panam. Math. J. 13(1), 103-126 (2003)

22. Lin, P., Gao, H., Liu, X.: Some results on controllability of a nonlinear degenerate parabolic system by bilinear control. J. Math. Anal. Appl. 326(2), 1149-1160 (2007)

23. Lions, J.L.: Remarques sur la contrôlabilité approchée. In: Proceedings of "Jornadas Hispano-Francesas sobre Control de Sistemas Distribuidos", University of Málaga, Spain (1990)

24. Lions, J.L.: Remarks on approximate controllability. J. Anal. Math. 59, 103-116 (1992)

25. Martinez, P., Raymond, J.P., Vancostenoble, J.: Regional null controllability of a linearized Crocco-type equation. SIAM J. Control Optim. 42(2), 709-728 (2003)

26. Martinez, P., Vancostenoble, J.: Carleman estimates for one-dimensional degenerate heat equations. J. Evol. Equ. 6(2), 325-362 (2006)

27. Wang, C.: Approximate controllability of a class of degenerate systems. Appl. Math. Comput. 203(1), 447-456 (2008)

28. Wang, C.: Approximate controllability of a class of semilinear systems with boundary degeneracy. J. Evol. Equ. 10(1), 163-193 (2010)

29. Wang, C., Du, R.: Approximate controllability of a class of semilinear degenerate systems with convection term. J. Differ. Equ. 254(9), 3665-3689 (2013)

30. Xu, J., Wang, C., Nie, Y.: Carleman estimate and null controllability of a cascade degenerate parabolic system with general convection terms. Electron. J. Differ. Equ. 2018, Article ID 195 (2018)

\section{Submit your manuscript to a SpringerOpen ${ }^{\circ}$ journal and benefit from:}

- Convenient online submission

- Rigorous peer review

- Open access: articles freely available online

- High visibility within the field

- Retaining the copyright to your article

Submit your next manuscript at $\boldsymbol{\nabla}$ springeropen.com 